\title{
Phytochemical, antimicrobial, antioxidant and immunomodulatory studies of leaf extracts of Cyclea peltata (Lam.) Hook. f. \& Thomson
}

\author{
Sukanya BCV and Bhat PR * \\ PG Department of Biotechnology, Alva's College, Moodbidri-574 227, Karnataka, India.
}

Publication history: Received on 02 December 2019; revised on 11 December 2019; accepted on 13 December 2019

Article DOI: https://doi.org/10.30574/gscbps.2019.9.3.0228

\begin{abstract}
The objective of the present investigation is to study the phytochemical constituents, antimicrobial, antioxidant activity and immunomodulatory effects of Cyclea peltata leaf extract. The fresh whole plants were collected from Kannur, Kerala, India. The crude extract of leaves of C. peltata prepared using methanol and aqueous solvents and were used to investigate the antibacterial activity against Streptococcus mutans, Staphylococcus aureus, Escherichia coli, Pseudomonas aeruginosa and Klebsiella pneumoniae by well diffusion method. Antioxidant by DPPH method and immunomodulatory study using Swiss albino rats. The extracts showed the presence of phytoconstituents like tannin, proteins, resins, carbohydrates, alkaloids and terpenoids. Both the extracts showed varying degree of inhibitory potential against all the tested bacteria. Methanol extract of plant had higher inhibitory action against Pseudomonas aeruginosa and Streptococcus mutans. While Staphylococcus aureus showed low sensitivity against aqueous extract of $C$. peltata. The body weight of the animals showed constant in the case of lower concentration of the drug ( $1 \mathrm{mg} / \mathrm{kg})$, whereas at higher concentration, the animals showed reduced body weight, with more reduction in highest concentration. Similarly for the organs like liver, the higher dose showed increased mass of liver when compared to lower doses of the drug. The tested animals showed good immunomodulatory effect against the leaf extract. This study further suggests the use of plant extract in treating disease caused by tested microbial organisms.
\end{abstract}

Keywords: Albino rats; Aqueous extract; Cyclea peltata; Immunomodulatory; Methanol extract; Phytochemical constituents

\section{Introduction}

After decades of serious obsession with the modern medicinal system, people have started looking at the ancient healing systems like Ayurveda, Siddha and Unani. This is because of the adverse effects associated with synthetic drugs. Herbal drugs play an important role in health care programs especially in developing countries. Ancient Indian literature incorporates a remarkably broad definition of medicinal plants and considers all plant parts to be potential sources of medicinal substance. In the last few decades there is an exponential growth in the field of herbal medicine [1]. It is getting popularized in developing countries owing to its natural origin and lesser side effects. Now-a-days, herbal medicines are being manufactured on a large scale in mechanical units. The manufacturers are facing many problems such as availability of good quality of raw material, authentication, availability of standards, standardization methodology of drugs, formulations and quality control parameters.

Immunology is the study of the immune system and is one of the most rapidly developing areas of medical biotechnology research. The immune system protects us from infection through various lines of defense. It has great promises with regard to the prevention and treatment of a wide range of disorders such as inflammatory diseases of skin, gut, respiratory tract, joints, and central organs. In addition infectious diseases are now primarily considered immunological

\footnotetext{
${ }^{*}$ Corresponding author

E-mail address: bhat_pr@rediffmail.com
} 
disorders while neoplastic diseases, organ transplantation and several autoimmune diseases may involve immunosuppressive state.

Immunomodulators are natural or synthetic substances that help to regulate or normalize the immune system. Immunomodulators correct immune systems that are out of balance. Natural immune modulators are less potent than prescription immune modulators and also less likely to cause side effects. Prescription immunomodulator medications, such as azathioprine, 6-mercaptopurine and methotrexate work by suppressing the immune system and decreasing inflammation in the digestive tract in people with bowel disease, ulcerative colitis and Cron's disease. The benefits of immunomodulator system from their ability to stimulate natural or adaptive defence mechanisms, such as cytokines, which enables to help the body itself.

Lymphocytes are one of many types of white blood cells produced in the bone marrow by the process of hematopoiesis. Lymphocytes leave the bone marrow, circulate in the blood and lymphatic system, and reside in various lymphoid organs. Because they produce and display antigen binding cell surface receptors, lymphocytes have the defining immunologic attributes of specificity, diversity, memory, and self/nonself recognition. The two major populations of lymphocytes are B lymphocytes and T. lymphocytes [2]. Phansalkar et al. [3] studied immunomodulatory effect of Withania somnifera (L.) Dunal in mice with myelosuppression induced by one or more of the three compounds like cyclophosphamide, azathioprin or prednisolone by hematological and serological test. Li et al. [4,5] studied the immunomodulatory effect of polysaccharides and showed that the polysaccharide may prime and trigger $\mathrm{M}$ phi and has restorative effects on the deficiency of the immune system associated with aging in mice, rats and piglets. Various investigators studied the immunomodulatory effect of different solvent extracts of plant species in mice [6-13].The objectives of present investigation is to analyse the phytochemical constituents, to evaluate the antimicrobial and antioxidant activity and to study the immunomodulatory activity of aqueous extracts of Cyclea peltata leaves on Albino rats.

\section{Material and methods}

\subsection{Plant material}

Cyclea peltata (Lam.) Hook. f. \& Thomson belongs to family Menispermaceae, is a much-branched, climbing shrub (Plate1A) found throughout South and east India and in the Andaman and Nicobar Islands. Roots are tuberous; Leaves are peltate, hairy, $2-5 \mathrm{~cm}$ long, flowers are very small. Male flowers in panicles are very long. Fruits are drupe and reniform (Plate1B). The species of this plant are easily distinguished by the cup-shaped calyx and corolla. The plant contain the chemical constituents like fangchinoline, cycleapeltine, cycleadrine, cycleacurine, cycleanorine, cycleahominechloride, chondocurine, mangoflorine, Isotetradrine, perpamine, cycleamine and burmannaline. The plant is widely used in the treatment of cough, fever, kidney disorder, urinary disorder and snake poisoning. Powdered roots for the treatment of diabetes, tooth ache; decoction of the roots and leaves used for treating malaria and asthma.

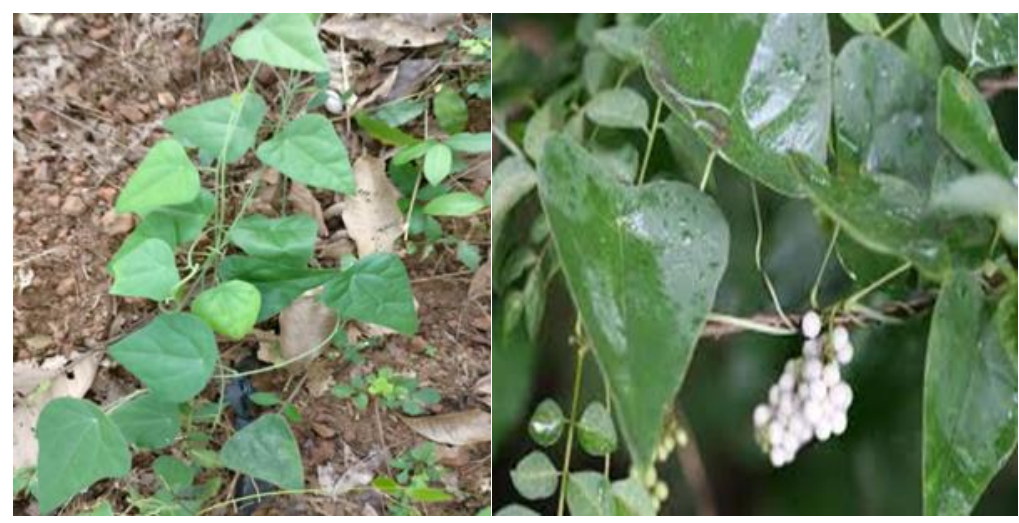

Figure 1A Habit of Cyclea peltata, 1B Fruits of $C$. peltata

The plant leaves were collected from Kannur, Kerala in the month of September 2018. The plant was confirmed in the department; thespecimen's herbarium was prepared with number ALCM/PGBT 10 and deposited in the department of PG Biotechnology. 
The collected leaves were cleaned with tap water and shade dried for a week. By using the kitchen blender the plant material was grounded to a fine powder form. The powder was then processed for extraction using solvents.

\subsection{Preparation of extract of $C$. peltata}

Eighty grams of powdered sample was mixed with $800 \mathrm{ml}$ of distilled water and boiled for $45 \mathrm{minutes}$. It was then filtered and the filtrate was kept in water bath for evaporation. The concentrated extract was then transferred to preweighed china dish. The extract was allowed to dry. This was repeated three times. Ten grams of the powder was taken in $100 \mathrm{ml}$ of methanol for extraction. It was then filtered and stored at $4^{\circ} \mathrm{C}$.

\subsection{Phytochemical screening of plant extract}

Qualitative tests were carried out for the preliminary screening of phytochemicals like carbohydrates, alkaloids, tannins, resins and saponins in the aqueous, methanol extracts reconstituted in respective solvents using standard procedures to identify the constituents [14].

\subsection{Antibacterial screening of the leaf extracts}

\subsubsection{Preparation of inoculums}

A loop full of culture was inoculated into nutrient broth and incubated at $37^{\circ} \mathrm{C}$ for 24 hours to obtain a bacterial culture. This procedure was carried for the selected bacterial cultures to obtain inoculums of particular broth culture. Bacterial cultures were collected from the P.G. department of Biotechnology. The strains are Streptococcus mutans, Staphylococcus aureus, Escherichia coli, Pseudomonas aeruginosa and Klebsiella pneumoniae.

\subsubsection{Antimicrobial activity by agar well diffusion method}

Petri dishes were plated with Nutrient agar media and allowed to solidify for 30 minutes. The test organisms were then spread on the surface of the media using sterile ear buds. Cork borer $(4 \mathrm{~mm})$ was used to bore wells in media. $50 \mu \mathrm{l}$ of aqueous extract of Cyclea peltata with different concentrations i.e., 500, 800,900,1000ug/ml was dispensed into the well using a micropipette respectively. A negative control of distilled water and a positive control of $20 \mu \mathrm{g} / \mathrm{ml}$ Penicillin $\mathrm{G}$ were kept and the extract was allowed to diffuse for half an hour at room temperature. Then the plates were incubated at room temperature for 24 hours. The zones of inhibitions were measured. For each organism three replicates were made.

\subsection{Antioxidant activity by DPPH method [15]}

Aqueous extracts of Cyclea peltata leaves were prepared. Two concentrations $(300 \mu \mathrm{g} / \mathrm{ml}$ and $600 \mu \mathrm{g} / \mathrm{ml})$ were prepared by using water. $2.5 \mathrm{ml}$ of sample was transferred into a test tube. To that $2.5 \mathrm{ml}$ of DPPH was added and mixed well. It was then incubated at room temperature in darkness for 30 minutes. Absorbance was then measured at 520nm using a mixture of distilled water and absolute ethanol as blank.

$\%$ inhibition $=$ Control absorbance(Ac) - Sample absorbance(As)

Control absorbance (Ac)

\subsection{Immunomodulatory activity}

\subsubsection{Animals}

Random bred Swiss albino rats (100-150g body weight) of both sexes were used for immunological studies. Animals were randomly divided into 4 treatment groups (minimum 5 animals per group) based on the concentration of the drug administered. Animals were maintained in cages with paddy husk as bedding. Animals were housed at temperature 24 $\pm 2^{\circ} \mathrm{C}, 12$ hour light or dark cycle and fed with standard pellet diet and water adlibitum. The experiments were started after obtaining the Institutional Ethical committee consent.

\begin{tabular}{cc}
\hline Group & No. of animals \\
\hline Group 1(Control) & 5 \\
Group 2(1mg/kg) & 5 \\
Group 3(2mg/kg) & 5 \\
Group 4(4mg/kg) & 5 \\
\hline
\end{tabular}




\subsubsection{Dosage}

The animals were divided into four groups. Each group comprised of a minimum of 5 animals. The plant extract was suspended in water and was administered orally for 14 days. Group I (control) received water; group II plant extract @ $1 \mathrm{mg} / \mathrm{kg}$ body weight; group III, @ $2 \mathrm{mg} / \mathrm{kg}$; and group IV received $4 \mathrm{mg} / \mathrm{kg}$ weight of the animal. For animal experiment methods of Bin-Hafeez et al. [16] was followed. The dose volume was calculated to be not more than $1 \mathrm{ml}$ of drug preparation per animal. Control animals received $1 \mathrm{ml}$ of water.

\subsubsection{Immunization}

Sheep RBC (SRBC) were collected in Alsever's solution, washed three times in phosphate buffered saline (PBS) and adjusted to a concentration of $0.5 \times 109$ cells $/ \mathrm{ml}$. On the 7 th day all the rats were immunized with $0.5 \times 109$ cells $/ \mathrm{ml}$ of SRBC peritonially using an insulin syringe. This is considered as the first dose. On the 11th day a booster dose was given.

\subsubsection{Body weight and lymphoid organ weight}

The animals were humanized after 14th day of treatment. Before sacrificing the animals, body weight of all the animals were recorded and blood was collected by heart puncturing using 21gauge needle and syringe. The collected blood was used for performing different tests such as total haemocyte count, differential count, blood glucose and hemoglobin. The serum was also prepared to run an assay for hemagglutinating antibody titre and serum albumin and globulin. After collecting blood, animals were sacrificed and the weight of organs like liver, thymus and spleen were recorded. Lymphoid tissues like, spleen, thymus including liver and kidney were fixed in phosphate buffered formalin for histological investigations to be conducted as a continued part of this work in a later period.

\subsubsection{Blood glucose test (Trinder's method)}

Three test tubes were taken and marked as B (blank), T (test), and S (standard). $1 \mathrm{ml}$ of glucose solution was added to all the tubes. To the tube 'T' $0.01 \mathrm{ml}$ of sample plasma was added. $0.01 \mathrm{ml}$ of standard glucose was added to the tube $\mathrm{S}$. All the tubes were incubated at $37^{\circ} \mathrm{C}$ for 5 minutes. Absorbance was read at $630 \mathrm{~nm}$ in a UV-Vis spectrophotometer (Systronics, 2202).

\subsubsection{Hemoglobin test (Cyanmethemoglobin method-CMG method)}

As much as $5 \mathrm{ml}$ of Drabkin's reagent was added to the tubes marked as B (blank), S (Standard) and T (Test). Exactly $0.02 \mathrm{ml}$ of blood was added to the tube T. CMG standard up to a volume of $0.02 \mathrm{ml}$ was added to the tube $\mathrm{S}$. Then 0.02 $\mathrm{ml}$ of distilled water was added to the tube B. All the tubes were incubated at room temperature for 10 minutes. The absorbance was read at $540 \mathrm{~nm}$ in UV-Vis spectrophotometer.

\subsubsection{Determination of total serum protein and albumin: globulin ratio}

This was estimated by Biuret method and absorbance was read at $540 \mathrm{~nm}$ in a UV spectrophotometer.

\subsubsection{Total leukocyte count and Differential count of white blood cells}

Total count was determined by WBC diluting fluid using Hemocytometer. Blood smear was prepared on a clean glass slide, allowed to dry and was fixed in methanol for 3 minutes. The slide was dried and dipped in Field's solution B for 5 seconds. It was then rinsed with water and allowed to dry. Then it was stained with Field's solution A for 15 seconds. After staining slide was rinsed with water and dried again. Stained slide was then observed under microscope.

\subsubsection{Hemagglutination antibody titer [17]}

As much as $100 \mu \mathrm{l}$ of serum was heat inactivated at $56^{\circ} \mathrm{C}$ in water bath for 30 minutes. About $50 \mu \mathrm{l}$ of PBS was added to all 12 wells of microtiter plate row. First well was taken as control and was not added with serum, instead it received only PBS. Next well received $50 \mu$ l of heat inactivated serum. From the same well using a micropipette, $50 \mu l$ of the mixture was taken after completely mixing it with the pipette and is serially diluted by 2 fold in the subsequent wells. Finally $50 \mu \mathrm{l}$ of SRBC with a cell density of $0.5 \times 109 / \mathrm{ml}$ was added to all the wells. The plate was gently tapped to mix the cells and was incubated at $37^{\circ} \mathrm{C}$ for 2 hours. The value of antibody titer was assigned to the highest serum dilution showing at least $50 \%$ of visible hemagglutination. 


\subsubsection{Hypersensitivity reaction}

On the day of termination of the treatment, animals were sensitized with $0.025 \times 109$ cells $/ \mathrm{ml}$ of SRBC on the right hind footpad by gently injecting the same using a insulin syringe. Increase in footpad thickness of rat was measured after 3 hours of the treatment and increase in volume of foot pad was measured manually.

\section{Results}

The phytochemical screening of extracts of Cyclea peltata was carried out by following the standard procedures. Aqueous extract showed the presence of carbohydrates, alkaloids, saponins, tannins, resins and terpenoids, where as the methanol extract showed the presence of all the above mentioned phytochemicals except carbohydrates (Table 1).

Table 1 Phytochemical analysis of extracts of Cyclea peltata leaves

\begin{tabular}{lcc}
\hline & Aqueous extract & Methanol extract \\
\hline Carbohydrates & + & - \\
Tannins & + & + \\
Alkaloids & + & + \\
Terpenoids & + & + \\
Resins & + & + \\
Saponins & + & + \\
\hline & '+' indicates present, ' ${ }^{-'}$ indicates absent
\end{tabular}

The bacterial cultures showed various levels of sensitivity towards different concentration of aqueous extracts of $C y c l e a$ peltata. Pseudomonas aeruginosa and Streptococcus mutans showed high sensitivity against the aqueous extract of $C$. peltata $(3.9 \mathrm{~cm})$. Staphylococcus aureus showed low sensitivity against aqueous extract of $C$. peltata $(3.6 \mathrm{~cm})($ Table 2$)$.

Table 2 Antibacterial activity of the aqueous extract of Cyclea peltata at different concentration

\begin{tabular}{|c|c|c|c|c|c|c|}
\hline \multirow[t]{2}{*}{ Bacterial strain } & \multicolumn{6}{|c|}{ Diameter of zone of inhibition $(\mathrm{cm})$} \\
\hline & $500 \mu \mathrm{g} / \mathrm{ml}$ & $800 \mu \mathrm{g} / \mathrm{ml}$ & $900 \mu \mathrm{g} / \mathrm{ml}$ & $1000 \mu \mathrm{g} / \mathrm{ml}$ & Positive & Negative \\
\hline Klebsiella pneumoniae & 1.6 & 3.2 & 3.5 & 3.7 & 1.9 & - \\
\hline Staphylococcus aureus & 2.3 & 3.5 & 3.6 & 3.6 & 1.8 & - \\
\hline ATCC29213 & & & & & & \\
\hline $\begin{array}{l}\text { Streptococcus mutans } \\
\text { MTCC } 497\end{array}$ & 2.6 & 3.4 & 3.7 & 3.9 & 1.5 & - \\
\hline $\begin{array}{l}\text { Escherichia } \\
\text { ATCC25922 }\end{array}$ & 1.8 & 3.4 & 3.6 & 3.8 & - & - \\
\hline $\begin{array}{l}\text { Lactobacillus acidophilus } \\
\text { MTCC10307 }\end{array}$ & 0.9 & 1.8 & 2.9 & 3.8 & - & - \\
\hline Pseudomonas aeruginosa & 1.9 & 3.9 & 3.9 & 3.9 & 1.4 & - \\
\hline
\end{tabular}

The aqueous extract of Cyclea peltata exhibited lower antioxidant activity compared to the standard ascorbic acid. The aqueous extract of leaves of $C$. peltata showed $18.8 \%$ inhibition at $300 \mathrm{mg} / \mathrm{ml}$ and it showed $33.5 \%$ inhibition in $600 \mathrm{mg} / \mathrm{ml}$, while the methanolic extracts showed $33.5 \%$ inhibition at $300 \mathrm{mg} / \mathrm{ml}$ and $37.6 \%$ inhibition in $600 \mathrm{mg} / \mathrm{ml}$ compared to 83.3 and $88.6 \%$ of standard ascorbic acid (Fig. 2). 


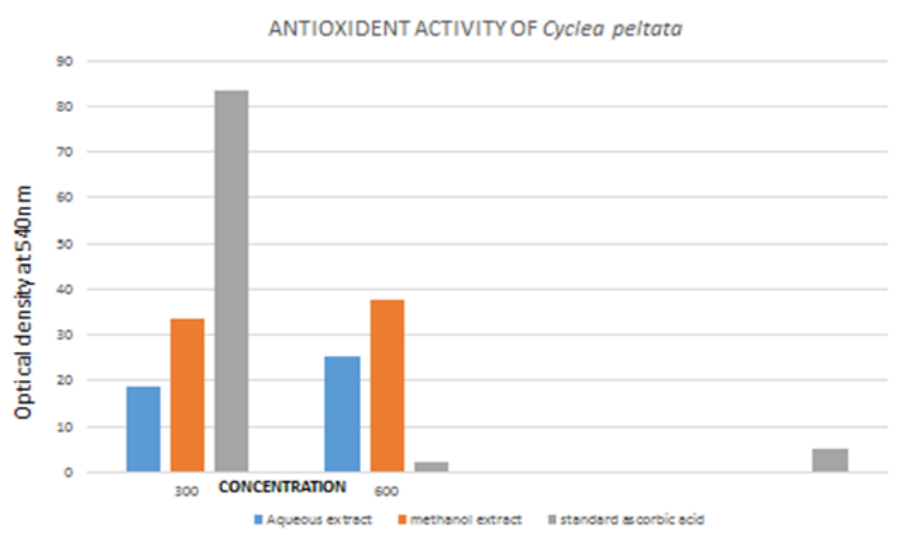

Figure 2 Antioxidant activity of Cyclea peltata leaf extract

During the study various morphometric, haematological, serological and other parameters required to assess the immune status of the albino rats upon administration of Cyclea peltata drug formulation for 14 days were recorded. The body weight of the animals of control group and that of treatment groups are given in the table 4 . The table also shows the weight of different vital lymphoid organs taken at the time of humanization after 14 days of treatment. The body weight of the animals showed constant in the case of lower concentration of the drug (1 mg/kg). However, at higher concentration, the animals showed reduced body weight, with more reduction in highest concentration. Similarly for the vital organs like liver, the higher dose showed increased mass of liver when compared to lower doses of the drug.

Table 4 Morphometric measures of albino rats treated with extracts of Cyclea peltata

\begin{tabular}{lcclll}
\hline & \multicolumn{2}{c}{ Body weight (g) } & Liver (g) & Spleen(g) & Kidney(g) \\
\cline { 2 - 5 } Initial & Final & & & \\
Group 1 & 200 & 200 & 07.2 & 0.86 & 0.81 \\
Group 2 & 215 & 215 & 08.06 & 0.90 & 0.97 \\
Group 3 & 200 & 200 & 09.2 & 01.0 & 01.02 \\
Group 4 & 200 & 170 & 09.5 & 01.2 & 01.17 \\
\hline
\end{tabular}

The total leukocyte count and differential count are showed in table 5. When compared to control group total leukocyte count was found increased in the lowest concentration $(1 \mathrm{mg} / \mathrm{kg})$ of drug administration. However increased in the drug concentration has further decreased the total leukocyte count. The percentage of neutrophils was found highest in lowest concentration $(1 \mathrm{mg} / \mathrm{kg})$ of drug tested with lowest percentage in highest concentration of a drug.

Table 5 Hematological parameters of albino rats treated with extracts of Cyclea peltata

\begin{tabular}{lllllll}
\hline Groups & Leukocyte & \multicolumn{4}{l}{ Total Differential Count } \\
& count & Lymphocyte & Monocyte & Neutrophil & Eosinophil & Basophil \\
\hline Group 1 & 2050 & 40 & 4 & 52 & 3 & 1 \\
Group 2 & 2750 & 33 & 6 & 56 & 3 & 1 \\
Group 3 & 2450 & 44 & 6 & 46 & 2 & 1 \\
Group 4 & 2300 & 40 & 6 & 50 & 3 & 1 \\
\hline
\end{tabular}

The glucose level is found to be at higher concentration of $123 \mathrm{mg} / \mathrm{dl}$ in lowest concentration group (1 mg/kg). Whereas increased concentration of the drug had reduced the blood glucose level. Similar trend is noticed for hemoglobin, serum protein and albumin globulin ratio. Hemoglobin is found to be highest in group I where drug administration was $1 \mathrm{mg} / \mathrm{kg}$ (Table 6, Fig. 3). 
Table 6 Hemoglobin and serum protein

\begin{tabular}{lllll}
\hline Groups & $\begin{array}{l}\text { Percentage } \\
\text { glucose(mg/dl) }\end{array}$ & $\begin{array}{l}\text { Percentage } \\
\text { Hemoglobin(g/dl) }\end{array}$ & $\begin{array}{l}\text { Serum protein } \\
\text { (g/100ml) }\end{array}$ & $\begin{array}{l}\text { Albumin globulin } \\
\text { ratio }\end{array}$ \\
\hline Group 1 & 94 & 5.0 & 6.0 & $6: 1$ \\
Group 2 & 123 & 8.0 & 8.4 & $8: 1$ \\
Group 3 & 106 & 6.7 & 7.3 & $7: 2$ \\
Group 4 & 101 & 4.5 & 7.2 & $7: 1$ \\
\hline
\end{tabular}

The results of HA titer is given in the table 6. After the immunization of the animals both for the control and treatment groups, hemagglutination antibody titer were estimated. Among the animals of group I and II which received drug at concentration $1 \mathrm{mg} / \mathrm{kg}$ and $2 \mathrm{mg} / \mathrm{kg}$ respectively showed highest antibody titer against SRBC. However, the increased concentration of drug administered did not show proportionate increase in the hemagglutination antibody titer.

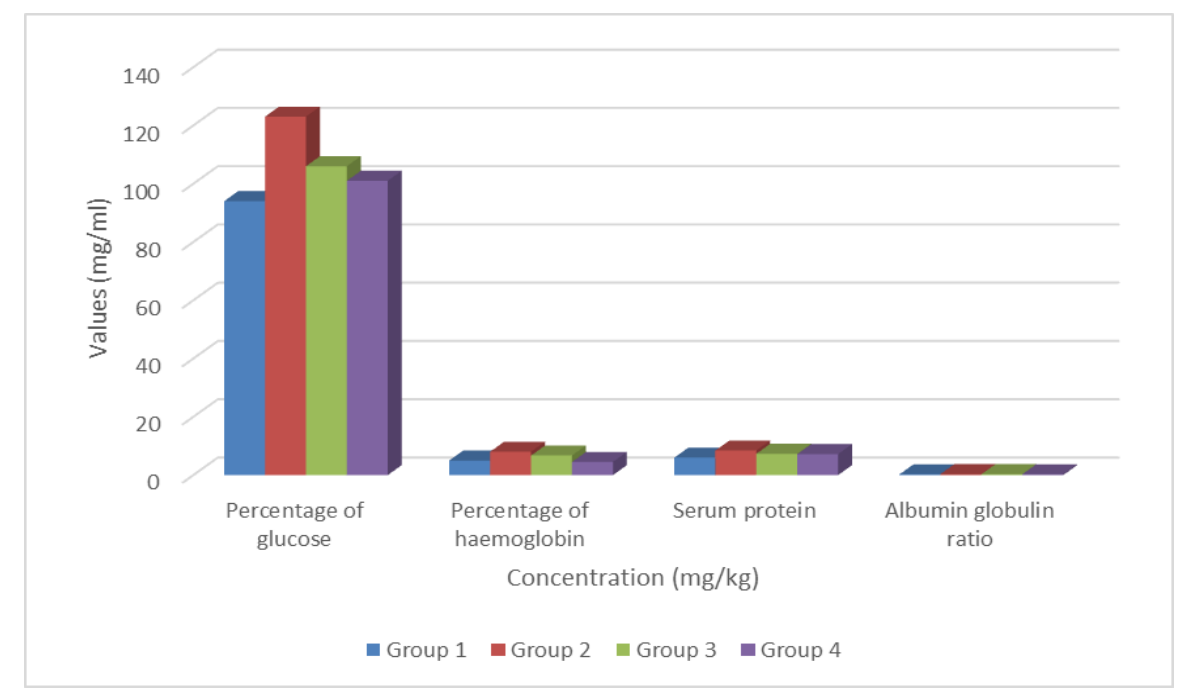

Figure 3 Serum protein levels

Delayed hypersensitivity reaction was noted highest in group I which received the lowest concentration (1 mg/kg) of drug when compared to control group. In this study a remarkable increase in paw volume was seen in case of drug administered at the rate of $4 \mathrm{mg} / \mathrm{kg} / \mathrm{day}$. In case of other groups hypersensitivity reaction could not be distinguished from that of the control group (Table 7 and Fig. 4).

Table 7 Haemagglutination antibody titer and hypersensitivity reaction

\begin{tabular}{lll}
\hline Groups & $\begin{array}{l}\text { Haemagglutination } \\
\text { antibody titer }\end{array}$ & $\begin{array}{l}\text { Hypersensitivity reaction } \\
\text { (Percentage increase in paw volume }\end{array}$ \\
\hline Group 1 & $1: 3096$ & 10 \\
Group 2 & $1: 5536$ & 16 \\
Group 3 & $1: 5536$ & 10 \\
Group 4 & $1: 1034$ & 10 \\
\hline
\end{tabular}




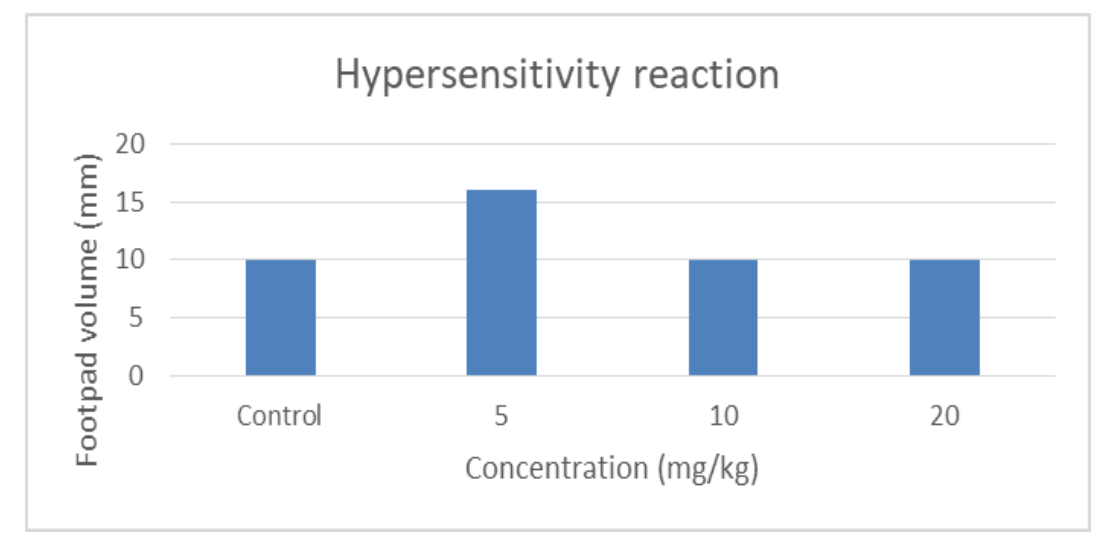

Figure 4 Hypersensitivity reaction

\section{Discussion}

Preliminary phytochemical screening for the methanol and aqueous Cyclea peltata leaf extract was carried out by following the standard procedures. Aqueous extract showed the presence of carbohydrates, alkaloids, saponins, tannins, resins and terpenoids whereas methanol extract showed the presence of all the above mentioned phytochemicals except carbohydrates and tannins. In one of the earlier experiment Hullatti et al. [18] screened petroleum ether and ethanolic extracts of $C$. peltata for phytochemicals and revealed the presence of phytosterols and alkaloids as major phytoconstituents in petroleum ether extract. The ethanolic extract showed the presence of alkaloids, flavonoids, tannins, diterpenes and saponins. Shine et al.[19] reported the presence of alkaloid content in all extracts, whereas saponins, steroids and terpenoids were detected in CP and CCP of C. peltata. Similar results were reported in other medicinal plants earlier [20, 21].

The antibacterial activity of the tested extracts of $C$. peltata showed significant reduction in bacterial growth in terms of zone of inhibition. The observed antimicrobial activity against the test organisms could be due to the presence of phytochemicals in the extract. The bacterial cultures showed various levels of sensitivity towards different concentration of aqueous extracts of $C$. peltata. Pseudomonas aeruginosa and Streptococcus mutans showed high sensitivity against the aqueous extract of $C$. peltata. Staphylococcus aureus showed low sensitivity against aqueous extract. Petroleum ether, hexane, chloroform, ethyl acetate, acetone, methanol and aqueous extracts of five concentrations $(1,2,5,10 \mathrm{mg} / \mathrm{ml})$ were used to investigate the antibacterial activity. All the extracts showed varying degree of inhibitory action against Staphylococcus haemolyticus, Klebsiella pneumoniae and Proteus vulgaris. Acetone extract showed maximum inhibitory action against Klebsiella pneumoniae and Streptococcus haemolyticus [22].

Cycleapeltatawhich has repeatedly been termed as a medicinal plant in the folk medicine is used in this study to analyse its antioxidant potential. The antioxidant activity of the plant was studied by the DPPH method. The stable nitrogen centered free radical. The aqueous extract of Cyclea peltata is showed antioxidant activity which was compared to the standard ascorbic acid.In the present study, the aqueous leaf extract of $C$. peltata showed $18.8 \%$ inhibition at $300 \mathrm{mg} / \mathrm{ml}$ and it showed $33.5 \%$ inhibition in $600 \mathrm{mg} / \mathrm{ml}$, while the methanolic extracts showed $33.5 \%$ inhibition at $300 \mathrm{mg} / \mathrm{ml}$ and $37.6 \%$ inhibition in $600 \mathrm{mg} / \mathrm{ml}$. Vijeesh et al. [21] found that the extracts even possesses antifungal activity too.

Chellappan et al. [23] evaluated the extracts of leaves and roots of C. peltata for physico-chemical, preliminary phytochemical analyses and antioxidant properties. Acute oral toxicity study was conducted as per OECD-423 guidelines and the extract was found to be devoid of any conspicuous acute toxicity in extract treated animals and no mortality up to $2 \mathrm{~g} / \mathrm{kg}$ by oral route. Hydroalcoholic extract of $C$. peltata in a dose dependant manner (125 and 250 $\mathrm{mg} / \mathrm{kg}$. p.o.) showed significant gastric protection against the ethanol-induced gastric ulcer model in rats. Different extracts of $C$. peltata were used for the experiments including anti-inflammatory by Shine et al. [19]. ACP and TET showed significant in vitro anti-inflammatory and antioxidant activity when compared to other extracts. ACP and TET $(100 \mu \mathrm{g} / \mathrm{ml})$ treatment significantly inhibited the mRNA expression of iNOS, COX-2, TNF- $\alpha$ in LPS treated RAW 264.7 cells. HPTLC estimation of bioactive compound tetrandrine was highest in ACP- $228.4 \mu \mathrm{g} / \mathrm{mg}$ followed by CP$29.62 \mu \mathrm{g} / \mathrm{mg}$, CCP-23.46 $\mu \mathrm{g} / \mathrm{mg}$, MCP-18.82 $\mu \mathrm{g} / \mathrm{mg}$ and HCP-1.25 $\mu \mathrm{g} / \mathrm{mg}$. TET has been isolated from ACP.

The antioxidant activity of methanolic extracts of various parts of Lantana camara showed thatall the plant parts possessed antioxidant properties including radical scavenging, xanthine oxidase inhibition and nitrites scavenging 
activities were correlated with the total phenol. The leaves extract of L. camara was more effective than that of other parts as well as in other plants too [24-27].

Cyclea peltata aqueous extract when administered to the albino rats at varying concentration have shown effect on their body weight and relative weight of vital organs like liver. The body weight remains constant (during 14 days trial) among the group 1 which received $1 \mathrm{mg} / \mathrm{kg}$ of test drug. However, with increase in concentration of the drug there was gradual reduction in the body weight indicating that drug is growth retarding instead of growth enhancing at concentration above $2 \mathrm{mg} / \mathrm{kg}$ body weight. The results are also strengthened with data obtained from liver which is a vital organ that respond immediately to any drug or toxin. In the present study the highest concentration (32 mg/kg) showed the highest liver mass showing possible hyperactivity at liver to ameliorate the toxic effect of the drug administered. Incidentally the lower concentration $(1 \mathrm{mg} / \mathrm{kg})$ of the drug showed the relative mass of liver to be similarly to control showing normal activity of liver. In case of thymus no difference among the control and treatment group were noted. Bin-Hafeez et al. [16] studied immunomodulatory effect of fenugreek extract in mice showed that no significant in body weight gained could not be noted among the animals there were no effect on spleen. Similar conclusions made by them which is comparable to present study. They found increased mass of liver in concentration up to $100 \mathrm{mg} / \mathrm{kg}$ and however they have opined that increase in liver mass could not be correlated to any other toxic effect as revealed by assays on some enzymes. One of the earliest immune response can be seen and measured by studying the hematological parameters of an animal. Accordingly parameters like total leukocyte count and differential count were measured for control group as well as group which received various concentrations of drug. Blood cells are the first cells to be responds to invading non-self-materials.

In the present study group 1 which received lower concentration (1 mg/kg) of drug showed highest leukocyte count of $2750 \mathrm{WBC} / \mathrm{mm} 3$ showing the initial triggering of blood cell to mount a potent immune response. The results showing lowered concentration of drug $(1 \mathrm{mg} / \mathrm{kg})$ are better to elicit good immune response than higher concentrations $(2 \mathrm{mg} / \mathrm{kg}, 4 \mathrm{mg} / \mathrm{kg})$ of drug administered. The results are further strengthened with highest percentage of neutrophil being circulated in the group receiving lower concentration $(1 \mathrm{mg} / \mathrm{kg})$ of drug.

Serum protein and serum albumin globulin ratio is one of the earliest indicators of normal serum chemistry of an individual. A change in serum protein concentration and albumin ratio would hint us about the altered immune response status of the individual. Accordingly in the present study serum protein level and albumin globulin ratio is found to be similar in case of control and higher concentration (4 mg/kg) of the drug but in the lower concentration (1 $\mathrm{mg} / \mathrm{kg}$ of drug test the group showed increase in serum protein and albumin ratio showing that higher immune response might have contributed to the serum protein in terms of different molecules such as immunoglobulins and other humoral factors. Similar results were observed for glucose and hemoglobin. Hemoglobin is also one of the important parameter that would reveal the health status of the individual. So in the present case group 1 receiving the lowest concentration ( $1 \mathrm{mg} / \mathrm{kg}$ ) of the drug show a better health index based on hemoglobin. In one of the earlier studies on leaf extracts of Moringa oleifera on Wistar rats by Nfambi et al. [28] revealed an increment in WBC, lymphocyte, and neutrophil counts at a dose of $1000 \mathrm{mg} / \mathrm{kg}$ body weight similar to the levamisole-positive control group. The neutrophil adhesion was statistically significant ( $\mathrm{p} \leq 0.05)$ for treatment groups that received $1000 \mathrm{mg} / \mathrm{kg}$ body weight $(29.94 \%)$ and $500 \mathrm{mg} / \mathrm{kg}$ body weight at $17.28 \%$. The mean percentage increment in footpad thickness was highest (26.9\%) after $8 \mathrm{~h}$ of injection of antigen in the footpad of rats dosed $500 \mathrm{mg} / \mathrm{kg}$ body weight and this later reduced to $25.6 \%$ after 24 $\mathrm{h}$. There was a dose-dependent increment in the mean hemagglutination antibody titer to sheep red blood cells (SRBC) from $10.73 \pm 0.57 \mathrm{HA}$ units $/ \mu \mathrm{L}$ for the $250 \mathrm{mg} / \mathrm{kg}$ body weight to $26.22 \pm 1.70 \mathrm{HA}$ units $/ \mu \mathrm{L}$ for the $1000 \mathrm{mg} / \mathrm{kg}$ body weight.

Hemagglutination antibody titer assay is one of the key parameter used to assess the humoral immune response of the animal. As the antigen is expected to induce the production of antiserum against it, in the present study sheep red blood cells were used to elucidate the production of antibody against RBC. In an individual where immune system is primed antibody against a particular antigen is expected to be at higher titer. Accordingly in the present study a very high hemagglutination antibody titer was recorded and group 2 and group 3 individual which received the lowest concentration ( $1 \mathrm{mg} / \mathrm{kg}$ and $2 \mathrm{mg} / \mathrm{kg}$ ) of test drug. On the contrary higher concentrations of the drug have surprisingly reduced the HA titer. Pradhan et al.[29] administered extract of herbal product to albino rats showed a increased HA titer when drug was used at a concentration of $50 \mathrm{mg} / \mathrm{kg}$. Similarly Bin- Hafeezet al.[16] also showed increased HA tire at doses of $50 \mathrm{mg} / \mathrm{kg}$ and above, of fenugreek extract administered on mice. They recorded the HA titer up to 1:2389. Further Fulzele et al.[6] studying immunostimulant activity of Ashtamangala ghrita in rats showed that HA titer could be well employed to study humoral immunomodulatory activity among the animals treated with drug. The authors showed that up to $300 \mathrm{mg} / \mathrm{kg}$ of the crude drug could enhance the humoral immune response. Upon examining the present results it is evident that the aqueous extract of Cycleapeltataat concentrations less than $2 \mathrm{mg} / \mathrm{kg}$ induced humoral immune response as evidenced by HA titer. Prasad et al.[30] used delayed type hypersensitivity assay to 
evaluate immunomodulatory activity of Momordica charantia ghrita extract on albino rats. There was an increase in paw volume in case of drug administered at the rate of $350 \mathrm{mg} / \mathrm{kg} /$ day. Pradhan et al. [28] also showed an increased hypersensitivity reaction in case of rats administered with herbal drugs. In the same line of earlier results, Bin-Hafeez et al.[16] also showed a significant increase in delayed type hypersensitivity at a concentration at $50 \mathrm{mg} / \mathrm{kg}$ compared to control. On the other hand Fulzeleet al. [6] showed Ashtamangala ghrita could also elucidate increased delayed type hypersensitivity response. Venkatachalam et al. [31] reported delayed hypersensitivity at $400 \mathrm{mg} / \mathrm{kg}$ dose of $\mathrm{Morus}$ alba aqueous extract on Wistar rats and thereby induced a better immunomodulatory activity.

In one of the study by Bafna and Mishra [10] the alkaloidal fraction of roots of Cissampelos pareira showed significant immunosuppressive activity at lower doses $(25$ and $50 \mathrm{mg} / \mathrm{kg})$ while no activity was observed at higher doses $(75$ and $100 \mathrm{mg} / \mathrm{kg}$ ). Humoral antibody titre was significantly $(\mathrm{p}<0.01)$ lowered by AFCP at the doses of $25 \mathrm{and} 50 \mathrm{mg} / \mathrm{kg}$. Delayed type hypersensitivity response was also significantly $(\mathrm{p}<0.01)$ suppressed by the AFCP at the dose of $75 \mathrm{mg} / \mathrm{kg}$. Hence they concluded the immunosuppressive and antioxidant activities of the alkaloidal fraction of $C$. pareira roots. Immunomodulatory activity of methanolic extract of Murraya koenigii (L.) Spreng. leaves increased the antibody titre against the ovalbumin and protection towards the cyclophosphamide induced myelosuppression. However, the extract did not show any significant increase in delayed type hypersensitivity reaction which indicated the inability of the extract to stimulate T cells [32]. Present study thus reveals that the extract holds promise as immunomodulatory agent, which acts by stimulating humoral immunity and phagocytic function. Similarly, Nfambi et al. [28] found a significant immunostimulatory effect on both the cell-mediated and humoral immune systems in the Wistar albino rats treated with methanolic leaf extract of $M$. oleifera. There are other earlier reports supports the present investigation [1, 19, 23, $33,34]$.

The overall results of the present study showed that the immune response is clearly boosted upon on administration of aqueous extract of Cyclea peltata. It is evident from the results that lower concentration of drug extract particularly $1 \mathrm{mg} / \mathrm{kg}$ body weight has the potential to trigger the both humoral and cellular immune response. Contrarily $2 \mathrm{mg} / \mathrm{kg}$ body weight or more has yielded a negative response in terms of mounting an immune response. Though these kinds of results have not been encountered in the literature it is not uncommon to have a varied physiological function of a plant derivative. There were few earlier works on this species adds support to the present study as it enhances immunomodulatory effect $[19,35,36]$. A drug, as per the science of herbal drug can result in different action based on the concentration of the drug prescribed. It is very common in Ayurvedic practices were concentration dependent effect is achieved as per the requirement. Therefore, there is every possibility that a aqueous extract of Cyclea peltata might trigger a toxicological or a negative effect on any of the physiological or immunological system of the body. Nevertheless the drug tested has evidently shown the immunomodulatory effect when used at lower concentration. As a concluding mark Cyclea peltata could be employed to boost immune system at low concentration and it should also be kept in mind that high concentration of same could lead to physiological effect in the body.

\section{Conclusion}

Cyclea peltata possesses antimicrobial and antioxidant activity due to the presence of phytochemicals in it. Therefore, there is every possibility that an aqueous extract of $C$. peltata might trigger a toxicological or a negative effect on any of the physiological or immunological system of the body. As a concluder mark $C$. peltata could be employed to boost immune system at low concentration and it should also be kept in mind that high concentration of same could lead to physiological effect in the body. Literature on this plant on any other health benefit effect or immunomodulatory activities is not available. Therefore the present findings on the immunomodulatory studies deduced that, the albino rats administered with varying concentrations of aqueous extracts of $C$. peltata would give a base line data and scientific evidence of immunological properties of the chosen plant.

\section{Compliance with ethical standards}

\section{Acknowledgments}

The authors are grateful to Dr. Ravi Rao S. Professor and Vice Principal, Alva's Ayurveda Medical College, Moodbidri for his help during animal experiments.

\section{Disclosure of conflict of interest}

The authors declare that there is no conflict of interest. 


\section{Statement of ethical approval}

The animal based experimental study was approved by the Institutional Ethical committee.

\section{References}

[1] Sumalatha, Rama Bhat P, Shwetha RB and Acharya S. (2012). Studies on immunomodulatory effects of Salacia chinensis L. on albino rats. Journal of Applied Pharmaceutical Science, 2(9), 98-107.

[2] Goldsby RA, Kindt TJ, Osborne BA and Kuby J. (2003). Immunology, Fourth edition, W.H. Freeman, New York, USA, 124-128.

[3] Phansalkar N, Ziauddin M, Patki P, Diwanay S and Patwardhan B. (1996). Studies on the immunomodulatory effects of Ashwagandha. Journal of Ethnopharmacology, 50(2), 69-76.

[4] Li J, Li DF, Xing JJ, Cheng ZB and Lai CH. (2006). Effects of $\beta$-glucan extracted from Saccharomyces cerevisiae on growth performance and immunological and somatotropic responses of pigs challenged with Escherichia coli lipopolysaccharide. Journal of Animal Science, 84, 2374-2381.

[5] Li J, Xing J, Li D, Wang X, Zhao L, LVS and Huang D. (2005). Effects of $\beta$-glucan extracted from Saccharomyces cerevisiae on humoral and cellular immunity in weaned piglets. Achieves Animal Nutrition, 59, 303-312.

[6] Fuzele SV, Sattuwar PM, Joshi SB and Dorle AK. (2003). Study of immunomodulatory activity of Haridradi Grita in rats. Indian Journal of Pharmacology, 35, 51-54.

[7] Gayathri V, Asha AV and Subhramoniam A. (2005). Preliminary studies on the immunomodulatory and antioxidant properties of Selaginella species. Indian Journal of Pharmacology, 37(6), 381-385.

[8] Abhishek SS, Wakade SA and Juvekar AR. (2008). Immunomodulatory activity of methanolic extract of Murraya koenigii. Indian Journal of Experimental Biology, 46, 505- 509.

[9] Ismail AS, Behrendt CL and Hooper LV. (2009). Reciprocal interactions between commensal bacteria and gamma delta intraepithelial lymphocytes during mucosal injury. Journal of Immunology, 182(5), 3047-54.

[10] Bafna A and Mishra S. (2010). Antioxidant and immunomodulatory activity of the alkaloidal fraction of Cissampelos pareira Linn. Scientia Pharmaceutica, 78(1), 21-31.

[11] Shendige, ERB, Asad M, Dhamangi SS and Chandrakala GK. (2010). Immunomodulatory activity of methanolic extract of Morus alba Linn. leaves. Journal of Pharacology and Science, 23(1), 63-68.

[12] Vinay J, Jat RC, Subodh D, Sudhir B and Suman J. (2010). Immunomodulatory effect of aerial part of Tephrosia purpurea Linn. Journal of Pharmacy Research, 3(1), 156-158.

[13] Vaidyanathan R, Jeba and Caroline R. (2011). Immunomodulatory activity of aqueous extract of Ocimum sanctum in rat. International Journal on Pharmaceutical and Biomedical Research, 2(1), 33-38.

[14] Hussain J, Khan FU, Ullah R, Muhammad Z, Rehman NU, Shinwari ZK, Khan IU, Zohaib M, Imad-Ud-Din and Hussain SM. (2011). Nutrient evaluation and elemental analysis of four selected medicinal plants of Khyber Pakhtoonkhwa, Pakistan. Pakistan Journal of Botany, 43(1), 427-434.

[15] Akar Z, Küçük M and Doğan H. (2017). A new colorimetric DPPH scavenging activity method with no need for a spectrophotometer applied on synthetic and natural antioxidants and medicinal herbs. Journal of Enzyme Inhibition and Medicinal Chemistry, 32(1).

[16] Bin-Hafeez B, Haque R, Parvez S, Pandey S, Sayeed I and Raisuddin S. (2003). Immunomodulatory effect of Trigonella foenum-graecum L. extract in mice. International Immunopharmacology, 3, 257-265.

[17] Bin-Hafeez B, Ahmad I, Haque R and Raisuddin S. (2001). Protective effect of Cassia occidentalis L. on cyclophosphamide -induced suppression of humoral immunity in mice. Journal of Ethnopharmacology, 75, 1318.

[18] Hullatti KK and Sharada MS. (2010). Comparetive phytochemical investigation of the source of Ayurvedic drug patha: a chromatographic fingerprinting analysis. Indian Journal of Pharmacological Science, 39-45.

[19] Shine VJ, Auja GI,Suja SR, Gopinath R and Latha PG. (2018). Bioassay guided fractionation of Cyclea peltata using in vitro RAW 264.7 cell culture, antioxidant assays and isolation of bioactive compound tetrandrine. Journal of Ayurveda and Integrative Medicine. 
[20] Iqbal H, Riyaz U, Khurram M, Naseem U, Basheer A and Khan FA. (2011). Phytochemical analysis of selected medicinal plants. African Journal of Biotechnology, 10(38), 7487-7492.

[21] Vijeesh V, Usha PN and Manju M. (2017). Phytochemical analysis and in vitro antifungal studies of medicinal plants Elephantopus scaber, Cyclea peltata and Artemisia. International Journal of Pharmacognosy and Phytochemical Research, 9(3), 319-322.

[22] Abraham J and Thomas D. (2012). Antibacterial activity of medicinal plant Cyclea peltata (Lam.) Hook. f. \& Thoms. Asian Pacific Journal of Tropical Disease, 2, 280-284.

[23] Chellappan DR, Jipnomon J and Parimaladevi B. (2011). Pharmacognostical, antioxidant and antiulcer screening of Cyclea peltata. RevistaBrasileira de Farmacognosia, 21(6).

[24] Badakhshan Mahdi-Pour,Jothy SL, Latha LY, Chen Y and Sasidharan S. (2012).. Antioxidant activity of methanol extracts of different parts of Lantana camara. Asian Pacific Journal of Tropical Biomedicine, 2(12), 960-965.

[25] Molyneux P. (2004). The use of the stable free radical diphenylpicrylhydrazyl (DPPH) for estimating antioxidant activity. Songklanakarin Journal of Science and Technology, 26, 211-219.

[26] Ko EY, Kim D and Roh SW. (2015). Evaluation on antioxidant properties of sixteen plant species from Jeju Island in Korea. Experimental and Clinical Journal, 14, 133-145.

[27] Rahman MM, Islam MB, Biswas M and Alam AHMK. (2015). In vitro antioxidant and free radical scavenging activity of different parts of Tabebuia pallida growing in Bangladesh. BMC Research Notes, 8, 621.

[28] Nfambi J, Bbosa GS, Sembajwe LF, Gakunga J and Kasolo JN. (2015). Immunomodulatory activity of methanolic leaf extract of Moringa oleifera in Wistar albino rats. Journal of Basic Clinical Physiology and Pharmacology, 26(6), 603-611.

[29] Pradhan D, Panda PK and Tripathy G. (2009). Evaluation of the immunomodulatory activity of the methanolic extract of Couroupita guianensis Aubl. flowers in rats. Indian Journal of Natural Products and Resources, 8, 6065 .

[30] Prasad V, Jain V and Dorle AK. (2006). Evaluation of Momordica charantia for immunomodulatory activity. Journal of Plant Science, 1(1), 80-85.

[31] Venkatachlam VV, Kannan K and Ganesh S. (2009). Preliminary immunomodulatory activities of aqueous extracts of Morus alba L. International Journal of Chemistry, 7(4), 2233-2238.

[32] Shah AS, Wakrele AS and Juvekar AR. (2008). Immunomodulatory activity of methanolic extract of Murraya koenigii (L.) Spreng. leaves. Indian Journal of Experimental Biology, 46(7), 505-509.

[33] Shwetha RB, Rama Bhat P, Sumalatha and Acharya S. (2012). Studies on immunostimulatory effect of Pajanelia longifolia (wild.) Schumann on albino rats. International Journal of Research in Pharmaceutical and Biomedical Science, 3(4), 1642-1652.

[34] Meena J and Santhy KS. (2015). Evaluation of the antioxidant potential of methanol extract of Cyclea peltata in DAL Model, The Pharma Innovation Journal, 4(1), 71-75.

[35] Shine VJ, Latha PG, Shyamal S, Suja SR, Anuja GI and Sini S. (2009). Gastric antisecretory and antiulcer activities of C. peltata (Lam.) Hook. f. \& Thomson in rats. Journal of of Ethnopharmacology, 125 (2), 350-355.

[36] Shine VJ, Latha PG, Suja SR, Anuja GI, Gopan R and Rajasekharan S. (2014). Ameliorative effect of alkaloid extract of Cyclea peltata (Poir.) Hook. f. \& Thoms. roots (ACP) on APAP/CCl4 induced liver toxicity in Wistar and in vitro free radical scavenging property. Asian Pacific Journal of Tropical Biomedicine, 4(2), 143-151.

\section{How to cite this article}

Sukanaya BCV and Bhat PR. (2019). Phytochemical, antimicrobial, antioxidant and immunomodulatory studies of leaf extracts of Cyclea peltata (Lam.) Hook. f. \& Thomson. GSC Biological and Pharmaceutical Sciences, 9(3), 52-63. 